\title{
Educational Attainment is Associated with Health Care Utilization and Self-Care Behavior by Individuals with Diabetes
}

\author{
Abdullah Alguwaihes ${ }^{1}$ and Baiju R. Shah ${ }^{*, 1,2,3}$ \\ ${ }^{I}$ Department of Medicine, University of Toronto, Toronto, ON, Canada \\ ${ }^{2}$ Institute for Clinical Evaluative Sciences, Toronto, ON, Canada \\ ${ }^{3}$ Department of Medicine, Sunnybrook Health Sciences Centre, Toronto, ON, Canada
}

\begin{abstract}
The aim of this study was to examine the association between educational attainment and utilization of the health care system and self-care behavior by individuals with diabetes. The Barriers to Diabetes Care Survey asked individuals with diabetes about their care. The questionnaire was completed using computer-assisted telephone interviewing techniques. Participants were found by random digit dialing across Ontario, Canada (eligible $n=1,031$ ). We dichotomized educational attainment at high school. We examined the relationship of educational attainment with measures of health care system utilization and of self-care behavior. We adjusted for age, sex, income, health insurance status, and diabetes type, duration and treatment regimen. Individuals with high educational attainment were more likely to have had an ophthalmologic examination during the previous year (odds ratio 1.37, 95\% confidence interval 1.04-1.82), and were more likely to report having a specialist (OR $2.08,95 \%$ CI 1.31-3.31) or other paramedical professional (OR 1.91, 95\% CI 1.19-3.07) as their most responsible provider of care, rather than a family doctor. Smoking (OR 0.64, 95\% CI 0.45-0.90) and blood sugar monitoring (OR $0.70,95 \%$ CI $0.50-0.98$ ) were associated with low educational attainment, while following a meal plan was associated with high educational attainment (OR 1.39, 95\% CI 1.07-1.80). Since appropriate utilization of the health care system and self-care behavior are essential for diabetes management, our findings suggest that people with low educational attainment are independently at risk for worse diabetes care. Health care providers should ensure that their communications, teaching materials and instructions are suitable for these higher-risk patients.
\end{abstract}

Keywords: Educational attainment, health care system utilization, self-care behavior.

\section{INTRODUCTION}

Diabetes is a significant chronic disease and its complications exert a huge burden on the health system. Patients with diabetes have early morbidity, mortality and decreased quality of life $[1,2]$. However, appropriate clinical care including patient self-management, surveillance for complications, and pharmacologic interventions can improve patients' health. Previous studies have shown that low income level and lack of insurance coverage can affect quality of diabetes care [3-6]. However, it is uncertain whether education independently influences diabetes care, particularly in publicly-funded health care systems where income and insurance coverage are less likely to limit care. Individuals with low educational attainment may be at particularly high risk, since educational attainment is inversely related to diabetes prevalence [7]. Several previous studies have examined the relationship between education level and quality of diabetes care [8-14], but most were too small and their samples too selective to draw generalizable conclusions. Therefore, we sought to examine the association between educational attainment and utilization of the health care system and self care behavior in a randomly selected sample of patients with diabetes, in a population with equal access to physician and hospital care.

*Address correspondence to this author at the Institute for Clinical Evaluative Sciences, G106 - 2075 Bayview Avenue, Toronto, Ontario, M4N 3M5, Canada; Tel: 416480 4706; Fax: 416480 6048;

E-mail: baiju.shah@ices.on.ca

\section{METHODS}

\section{Data Source}

The Barriers to Diabetes Care Survey asked patients diagnosed with diabetes across the province of Ontario, Canada about their diabetes care and any barriers to their care that they have encountered. Details have been published previously [6]. The questionnaire was administered in 2006, and included questions about demographics, clinical history, health service utilization, self-care behaviors, insurance coverage, employment status, and educational attainment. All interviewing was completed from centralized telephone facilities at the Institute for Social Research at York University, using computer-assisted telephone interviewing techniques. Random digit dialing procedures were utilized to select households. The households were screened to find out whether someone in the household had been diagnosed with diabetes. If there was more than one household member diagnosed with diabetes, the person with the most recent birthday was interviewed. No substitutions were made for household members more willing to participate, nor were proxy interviews allowed. All questionnaires were administered in English, and non-English interviewees were excluded. A maximum of 12 calls at various times of day were made to sample numbers before the number was considered not reachable. Attempts were made to encourage refusers to participate in the survey by calling them at least once after the initial refusal. The survey screened 29,339 telephone numbers, of which 24,629 were found to be households. Of 
them, 17,612 were not eligible, and eligibility could not be definitively established for another 5,765. From the remaining 1,252 households, the survey was completed by 1,150 . The average interview duration was 20.2 minutes.

\section{Statistical Analysis}

The primary exposure of interest in the study was educational attainment, which we dichotomized at high school. Baseline characteristics between the two groups were compared using chi-square tests.

We examined several outcome measures for their relationship with educational attainment, including measures of health care system utilization (nutrition counseling in the last 12 months, ophthalmological examination in the last 12 months, foot care in the last 12 months, awareness of diabetes education centers, family physician visit in the last 6 months, specialist visit in the last 12 months, and patientreported most-responsible provider of diabetes care), and self care behavior (blood sugar monitoring, following a meal plan, doing exercise, and cigarette smoking). The behavioral measures were collected in the survey on a scale (e.g. "always," "often," "some of the time" or "rarely"), but were dichotomized to simplify the analysis.

The associations between educational attainment and each outcome variable were examined using logistic regression to adjust for age, sex, income, insurance status, and diabetes type, duration and treatment regimen. Income level was derived ecologically from the median household neighborhood income. Although all Ontario residents are eligible for publicly-funded hospital and physician care without any co-payments or extra charges, insurance for drugs and diabetes testing supplies is publicly-funded only for a proportion of the population; hence, adjustment for insurance status remains important. Participants with missing data on any of the adjustment variables were excluded.

\section{RESULTS}

Of the 1,150 participants in the survey, $119(10 \%)$ were excluded for missing data. $578(56 \%)$ of the eligible participants reported high school education or less, and so were classified as being in the low educational attainment group. The final sample size had $80 \%$ power to detect an absolute unadjusted difference of $9.0 \%$ between groups.

The baseline characteristics of both groups are presented in Table 1. In general female sex, older age, not being on intensive insulin regimen, being overweight/obese, and being retired were associated with low educational attainment.

Among health care utilization measures (Table 2), an ophthalmologic exam in the previous year was significantly associated with high educational attainment, after adjustment for age, sex, income, insurance status, and diabetes type, duration and treatment regimen. Participants with high educational attainment were also more likely to report that a specialist or a paramedical practitioner was their most responsible provider.

Among self-care behaviors (Table 3), participants with high educational attainment were more likely to report following a meal plan and less likely to report being cigarette smokers. However, participants with low education attainment were more likely to report monitoring their blood sugar. Exercise was not associated with educational attainment.

Table 1. Baseline Characteristics of the Low and High Educational Attainment Groups

\begin{tabular}{|c|c|c|c|c|}
\hline \multirow{3}{*}{ Variable } & & \multicolumn{2}{|c|}{ Educational Attainment } & \multirow{3}{*}{ P-Value } \\
\hline & & \multirow{2}{*}{$\begin{array}{c}\text { Low } \\
\mathbf{N}=\mathbf{5 7 8}\end{array}$} & \multirow{2}{*}{$\begin{array}{c}\text { High } \\
N=453\end{array}$} & \\
\hline & & & & \\
\hline \multirow{2}{*}{ Sex } & Female & $52 \%$ & $42 \%$ & 0.001 \\
\hline & Male & $48 \%$ & $58 \%$ & \\
\hline \multirow{3}{*}{ Age } & $<45$ & $7 \%$ & $19 \%$ & $<0.001$ \\
\hline & $45-64$ & $42 \%$ & $51 \%$ & \\
\hline & $\geq 65$ & $51 \%$ & $30 \%$ & \\
\hline \multirow{2}{*}{ Type } & Type 1 & $12 \%$ & $16 \%$ & 0.06 \\
\hline & Type 2 & $88 \%$ & $84 \%$ & \\
\hline \multirow{3}{*}{$\begin{array}{c}\text { Duration of } \\
\text { Diabetes }\end{array}$} & $0-5$ yrs & $34 \%$ & $35 \%$ & 0.1 \\
\hline & $6-10 \mathrm{yrs}$ & $19 \%$ & $23 \%$ & \\
\hline & $\geq 11$ yrs & $47 \%$ & $42 \%$ & \\
\hline \multirow{4}{*}{$\begin{array}{c}\text { Diabetes } \\
\text { Treatment }\end{array}$} & Intensive insulin & $8 \%$ & $14 \%$ & 0.005 \\
\hline & Conventional insulin & $15 \%$ & $11 \%$ & \\
\hline & Oral medications & $45 \%$ & $47 \%$ & \\
\hline & Lifestyle & $32 \%$ & $27 \%$ & \\
\hline \multirow{4}{*}{ Income } & 1 (Lowest) & $15 \%$ & $14 \%$ & 0.2 \\
\hline & 2 & $61 \%$ & $57 \%$ & \\
\hline & 3 & $19 \%$ & $20 \%$ & \\
\hline & 4 (Highest) & $7 \%$ & $10 \%$ & \\
\hline \multirow{2}{*}{ Insurance } & No & $15 \%$ & $12 \%$ & 0.2 \\
\hline & Yes & $85 \%$ & $88 \%$ & \\
\hline \multirow{4}{*}{ Employment } & Employed & $24 \%$ & $44 \%$ & $<0.001$ \\
\hline & Retired & $53 \%$ & $34 \%$ & \\
\hline & Illness/Disability & $11 \%$ & $11 \%$ & \\
\hline & Other & $11 \%$ & $12 \%$ & \\
\hline \multirow{2}{*}{$\begin{array}{c}\text { Alternative } \\
\text { Medicine }\end{array}$} & No & $95 \%$ & $91 \%$ & 0.01 \\
\hline & Yes & $5 \%$ & $9 \%$ & \\
\hline \multirow{4}{*}{$\begin{array}{c}\text { Body } \\
\text { Mass Index }\end{array}$} & $<18.5$ & $1 \%$ & $1 \%$ & 0.009 \\
\hline & $18.5-24.9$ & $17 \%$ & $25 \%$ & \\
\hline & $25-29.9$ & $39 \%$ & $32 \%$ & \\
\hline & $\geq 30$ & $43 \%$ & $42 \%$ & \\
\hline
\end{tabular}

We repeated the analysis using self-reported income instead of ecologically-assigned neighborhood income. This reduced the sample size by approximately $17 \%$ to 857 , as many survey participants declined to disclose their income. In this analysis, only cigarette smoking remained statistically significantly associated with educational attainment. The adjusted odds ratios for the other outcomes lost statistical 
Table 2. Health Care Utilization Measures by Educational Attainment, Adjusted for Sex, Age, Income, Insurance Status, and Diabetes Type, Duration and Treatment Regimen

\begin{tabular}{|c|c|c|c|c|}
\hline Health Care Utilization & \multicolumn{2}{|c|}{ Educational Attainment } & Adjusted OR & \multirow{3}{*}{ P-Value } \\
\hline \multirow{2}{*}{ Measure } & Low & High & \multirow{2}{*}{$(95 \% \mathrm{CI})$} & \\
\hline & $N=\mathbf{5 7 8}$ & $\mathrm{N}=\mathbf{4 5 3}$ & & \\
\hline Nutrition counseling & $30 \%$ & $34 \%$ & $1.18(0.88-1.57)$ & 0.3 \\
\hline Ophthalmologic exam & $65 \%$ & $70 \%$ & $1.37(1.04-1.82)$ & 0.03 \\
\hline Foot care & $15 \%$ & $17 \%$ & $1.36(0.95-1.95)$ & 0.09 \\
\hline Education centre awareness & $78 \%$ & $80 \%$ & $1.00(0.72-1.38)$ & 1.0 \\
\hline Family physician visit & $35 \%$ & $40 \%$ & $1.21(0.93-1.58)$ & 0.2 \\
\hline Specialist visit & $9 \%$ & $12 \%$ & $1.13(0.73-1.76)$ & 0.6 \\
\hline \multicolumn{5}{|l|}{ Most responsible provider } \\
\hline Family physician & $83 \%$ & $71 \%$ & ref & 0.001 \\
\hline Specialist & $7 \%$ & $14 \%$ & $2.08(1.31-3.31)$ & \\
\hline Paramedical & $7 \%$ & $11 \%$ & $1.91(1.19-3.07)$ & \\
\hline Other & $2 \%$ & $3 \%$ & $1.96(0.90-4.25)$ & \\
\hline
\end{tabular}

Table 3. Self-Care Behavior Measures by Educational Attainment, Adjusted for Sex, Age, Income, Insurance Status, and Diabetes Type, Duration and Treatment Regimen

\begin{tabular}{|c|c|c|c|c|}
\hline Self-Care Behavior & \multicolumn{2}{|c|}{ Educational Attainment } & Adjusted OR & \multirow{3}{*}{ P-Value } \\
\hline \multirow{2}{*}{ Measure } & Low & High & \multirow{2}{*}{$(95 \% \mathrm{CI})$} & \\
\hline & $\mathrm{N}=\mathbf{5 7 8}$ & $N=453$ & & \\
\hline Blood sugar monitoring & $83 \%$ & $78 \%$ & $0.70(0.50-0.98)$ & 0.04 \\
\hline Following a meal plan & $46 \%$ & $53 \%$ & $1.39(1.07-1.80)$ & 0.02 \\
\hline Exercise & $57 \%$ & $64 \%$ & $1.24(0.95-1.62)$ & 0.1 \\
\hline Smoking & $20 \%$ & $17 \%$ & $0.64(0.45-0.90)$ & 0.01 \\
\hline
\end{tabular}

significance, but the point estimates were similar albeit slightly attenuated.

\section{DISCUSSION}

Even in a publicly-funded health care system with uniform access to hospital and physician care, educational attainment was associated with measures of health care utilization. The study results suggest that individuals with high educational attainment were more likely to have an ophthalmological examination, and were more likely to report a specialist or paramedical practitioner as their most responsible provider of care. Both these findings suggest that individuals with low educational attainment are more reliant on their primary care physicians for care, whereas those with high educational attainment may be more likely to be referred to specialists in general, either because of patient requests or physician recommendations. The finding of lower adherence with ophthalmological examinations among those with low educational attainment is consistent with previous literature $[11,12]$.

Some self-care behaviors were also independently associated with educational attainment. Individuals with high educational attainment were more likely to report following a meal plan and were less likely to smoke. This suggests that individuals with high educational attainment may have a greater awareness of, motivation for, or ability to implement healthy behaviors to improve their diabetes care. The strong inverse relationship between educational attainment and smoking is particularly concerning, given the high burden of cardiovascular disease for people with diabetes $[15,16]$, and has been described previously $[13,14,17]$. Therefore, special techniques or messages to encourage smoking cessation, targeting individuals with low educational attainment may be required. Surprisingly, we found that those with low educational attainment were more likely to report doing blood sugar monitoring. This potentially paradoxical observation may have occurred because people with lower educational attainment were more likely to follow their physicians' recommendations to monitor blood sugars, after adjusting for income and insurance status - two factors that might otherwise have been barriers to monitoring in this population. Confirming and exploring this association will be required in future studies.

There are several potential reasons why higher educational attainment could result in better diabetes quality of 
care, independently of income or other demographic and clinical factors. Individuals with higher education levels may have a greater understanding of the importance of preventative care, appropriate screening tests and self-management. These individuals may have better self-advocacy skills and greater self-efficacy. They might have better access to and understanding of educational materials, support groups, websites, and other community resources to facilitate diabetes care. Finally, their employment and social environments may be healthier, which would make it easier to manage their diabetes [18].

Of note, a large proportion of our study population was not following a meal plan or not doing exercise, regardless of educational attainment. Because these self-care behaviors are fundamental to appropriate management of diabetes, their absence could reflect lack of patient motivation, societal influences making it difficult to follow a healthy lifestyle, and/or clinical care more focused on pharmacological treatment than behavior change.

Previous literature examining the association of diabetes care or outcomes with educational attainment as the primary exposure of interest is scant. Karter et al. [13] surveyed nearly 9,000 patients as part of a large study evaluating individual, provider and structural factors associated with diabetes care and outcomes, and found results similar to ours. Lower educational attainment was associated with lower predicted probabilities of being a non-smoker, of engaging in regular exercise, and of health-seeking behavior for diabetesrelated non-clinical services (such as support groups or diabetes websites), after adjustment for demographics, diabetes severity, comorbidity and employment. Blood sugar monitoring and foot self-examination were not associated with educational attainment. Nádas et al. [14] evaluated 533 patients with type 1 diabetes, and found that people with lower education levels had worse glycemic control, were less physically active and were more likely to smoke cigarettes. However, these associations were unadjusted for potential confounders.

Several other studies have evaluated quality of care indicators with education level as a covariate or other exposure. Zgibor et al. [8] found that patients with type 1 diabetes who completed high school had better glycemic control and were more likely to have received specialist care. However, there was no effect of education level on blood glucose monitoring, receiving diabetes education and ophthalmology visits. Goudswaard et al. [9] observed a modest relationship between education and glycemic control, while Schillinger et al. [10] did not find such a relationship. Paz et al. [11] and Witkin et al. [12] found that people with lower educational attainment were less likely to comply with vision care guidelines. Gucciardi et al. [19] found that education level did not influence attendance at diabetes education programs. However, many of these previous studies had a small sample size or included patients from a single clinical setting, which makes it difficult to generalize their results.

Our study has several strengths, including our large sample that was drawn from a random selection of the population, making our results more suitable for generalization. The sample included both types of diabetes and patients followed in both primary and specialty care settings. Limitations to our study include a lack of objective measures of quality of diabetes care, such as clinical data or processes of care, so we could not assess whether educational attainment was associated with these important indicators. Despite the relatively large sample size, the study may have been underpowered to detect clinically important differences in some outcomes measures. In addition, our measures of educational attainment, health service utilization and self-care behavior were based on patient self-report only, and hence may be subject to obsequiousness bias or misclassification bias. The findings of the study may be prone to alpha-error because of multiple hypothesis testing, and so they can only be considered hypothesis-generating. Finally, the study was crosssectional in design, so no causal inferences can be drawn.

We have demonstrated that several health care utilization and self-care behavior measures for individuals with diabetes are independently associated with educational attainment. Therefore, patients with low educational attainment are at risk for a poorer quality of diabetes care. To ensure that these patients are able to equally benefit from the essential health care utilization and self-care behaviors needed to optimize diabetes care, health care practitioners must ensure that their communication, instructions and teaching materials are understandable by individuals with different levels of education.

\section{ACKNOWLEDGEMENTS}

Dr. Shah is supported by the Canadian Institutes of Health Research, Canadian Diabetes Association and the Banting and Best Diabetes Centre of the University of Toronto. The Institute for Clinical Evaluative Sciences is supported by the Ontario Ministry of Health and Long-Term Care.

\section{REFERENCES}

[1] Nathan D. Long term complication of diabetes mellitus. New Engl J Med 1993; 328: 1676-85.

[2] Harris MI, Cowie CC, Stern MP, Boyko EJ, Reiber GE, Bennett $\mathrm{PH}$, Eds. Diabetes in America. $2^{\text {nd }}$ ed. Washington, DC: National Institutes of Health, National Institute of Diabetes and Digestive and Kidney Diseases 1995.

[3] McCall DT, Sauaia A, Hamman RF, Reusch JE, Barton P. Are lowincome elderly patients at risk for poor diabetes care? Diabetes Care 2004; 27: 1060-5.

[4] Nelson KM, Chapko MK, Reiber G, Boyko EJ. The association between health insurance coverage and diabetes care: data from the 2000 behavioral risk factor surveillance system. Health Serv Res 2005; 40: 361-72.

[5] Karter AJ, Ferrara A, Darbinian JA, Ackerson LM, Selby JV. Selfmonitoring of blood glucose: language and financial barriers in a managed care population with diabetes. Diabetes Care 2000; 23: 477-83.

[6] Kwan J, Razzaq A, Leiter LA, Lillie D, Hux JE. Low socioeconomic status and absence of supplemental health insurance as barriers to diabetes care access and utilization. Can J Diabetes 2008; 32: 174-81.

[7] Borrel L, Dallo FJ, White K. Education and diabetes in a racially and ethnically diverse population. Am J Public Health 2006; 96: $1637-42$.

[8] Zgibor JC, Songer TJ, Kelsey SF, et al. The association of diabetes specialist care with health care practices and glycemic control in patients with type 1 diabetes: a cross-sectional analysis from the Pittsburgh Epidemiology of Diabetes Complications Study. Diabetes Care 2000; 23: 472-6.

[9] Goudswaard AN, Stolk RP, Zuithoff P, Rutten GEHM. Patient characteristics do not predict poor glycaemic control in type 2 diabetes patients treated in primary care. Eur J Epidemiol 2004; 19: $541-5$. 
[10] Schillinger D, Grumbach K, Piette J, et al. Association of health literacy with diabetes outcome. JAMA 2002; 288: 475-82.

[11] Paz SH, Varma R, Klein R, Wu J, Azen SP. Noncompliance with vision care guidelines in Latinos with type 2 diabetes mellitus: the Los Angeles Latino Eye Study. Ophthalmology 2006; 113: 1372-7.

[12] Witkin SR, Klein R. Ophthalmologic care for persons with diabetes. JAMA 1984; 251: 2534-7.

[13] Karter AJ, Stevens MR, Brown AF, et al. Educational disparities in health behaviors among patients with diabetes: the Translating Research into Action for Diabetes (TRIAD) Study. BMC Public Health 2007; 7: 308 .

[14] Nádas J, Putz Z, Fövényi J, et al. Cardiometabolic and educational level in adults patients with type 1 diabetes. Acta Diabetol 2008; Epub ahead of print. DOI 10.1007/s00592-008-0065-4.

[15] Gregg EW, Gu Q, Cheng YJ, Venkat Narayan KM, Cowie CC. Mortality trends in men and women with diabetes, 1971 to 2000. Ann Intern Med 2007; 147: 149-55.
[16] Haffner SM, Lehto S, Rönnemaa T, et al. Mortality from coronary heart disease in subjects with type 2 diabetes and in non-diabetic subject with and without prior myocardial infarction. New Engl $\mathrm{J}$ Med 1998; 339: 229-34.

[17] Karter AJ, Stevens MR, Gregg EW. Educational disparities in rates of smoking among diabetic adults: the translating research into action for diabetes study. Am J Public Health 2008; 98: 365-70.

[18] Glazier RH, Booth GL, Gozdyra P, Creatore MI, Tynan M, Eds. Neighbourhoods and Environments and Resources for Health Living - A Focus on Diabetes in Toronto. Toronto: Institute for Clinical Evaluative Sciences 2007. Accessed from http://www.ices.on. ca/webpage.cfm?site_id $=1 \&$ org_id $=67$ on 26 October 2008

[19] Gucciardi E, DeMelo M, Offenheim A, Stewart DE. Factors contributing to attrition behavior in diabetes self-management programs: a mixed method approach. BMC Health Serv Res 2008; 8: 33.

(C) Alguwaihes and Shah; Licensee Bentham Open.

This is an open access article licensed under the terms of the Creative Commons Attribution Non-Commercial License (http://creativecommons.org/licenses/by$\mathrm{nc} / 3.0 /$ ) which permits unrestricted, non-commercial use, distribution and reproduction in any medium, provided the work is properly cited. 